\title{
Pentacecilides, new inhibitors of lipid droplet formation in mouse macrophages produced by Penicillium cecidicola FKI-3765-1: II. Structure elucidation
}

\author{
Hiroyuki Yamazaki ${ }^{1}$, Satoshi Ōmura ${ }^{2}$ and Hiroshi Tomoda ${ }^{1}$ \\ The structures of pentacecilides, new inhibitors of lipid droplet formation in mouse macrophages produced by Penicillium \\ cecidicola FKI-3765-1, were elucidated by spectroscopic studies, including various NMR experiments. Pentacecilides have \\ a common pentacyclic meroterpene core, which contains an aromatic ring and a $\delta$-lactone ring. \\ The Journal of Antibiotics (2009) 62, 207-211; doi:10.1038/ja.2009.19; published online 20 March 2009
}

Keywords: pentacecilides; structure elucidation; fungal metabolites; lipid droplet formation

\section{INTRODUCTION}

Three new compounds, designated pentacecilides A to C (Figure 1) were isolated as inhibitors of lipid droplet formation in mouse macrophages from the culture broth of $P$. cecidicola FKI-3765-1. ${ }^{1}$ The taxonomy of the producing strain, fermentation, isolation and biological properties of pentacecilides were described in an earlier paper. ${ }^{1}$ In this study, the physicochemical properties and structure elucidation of pentacecilides are described.

\section{RESULTS}

Physicochemical properties

The physicochemical properties of pentacecilides A to C are summarized in Table 1 . They have a similar pattern with absorption maxima at 214-219 $\mathrm{nm}, 273-274 \mathrm{~nm}$ and 309-310 $\mathrm{nm}$ in UV spectra. IR absorption at $1619-1745 \mathrm{~cm}^{-1}$ and $3401-3434 \mathrm{~cm}^{-1}$ suggested the presence of carbonyl and hydroxy groups in their structures. These data indicated that they share a similar skeleton.

\section{Structure elucidation of pentacecilide $\mathbf{C}$}

The molecular formula of pentacecilide $\mathrm{C}$ was determined to be $\mathrm{C}_{27} \mathrm{H}_{34} \mathrm{O}_{8}$ on the basis of HRESI-TOF-MS measurement (Table 1). The ${ }^{13} \mathrm{C}$ NMR spectrum (in $\mathrm{CDCl}_{3}$ ) showed 27 resolved signals, which were classified into six methyl carbons, four methylene carbons, two $s p^{3}$ methine carbons, one $s p^{2}$ methine carbon, three oxygenated $s p^{3}$ methine carbons, two $s p^{3}$ quaternary carbons, one oxygenated $s p^{3}$ quaternary carbon, three $s p^{2}$ quaternary carbons, two oxygenated $s p^{2}$ quaternary carbons and three carbonyl carbons by analysis of the DEPT and heteronuclear single quantum coherence (HSQC) spectra.
The ${ }^{1} \mathrm{H}$ NMR spectrum (in $\mathrm{CDCl}_{3}$ ) displayed 33 proton signals, one of which was suggested to be a hydroxyl proton $(\delta 11.08)$, as reported in thailandolides. ${ }^{2}$ Taking the molecular formula into consideration, the presence of another hydroxy proton was suggested. The connectivity of proton and carbon atoms was established by the ${ }^{13} \mathrm{C}-{ }^{1} \mathrm{H}$ HSQC spectrum (Table 2). Analyses of ${ }^{1} \mathrm{H}-{ }^{1} \mathrm{H}$ COSY revealed the presence of partial structures I to IV, as shown in Figure 2. Furthermore, ${ }^{13} \mathrm{C}-{ }^{1} \mathrm{H}$ long-range couplings of ${ }^{2} \mathrm{~J}$ and ${ }^{3} \mathrm{~J}$ observed in the ${ }^{13} \mathrm{C}-{ }^{1} \mathrm{H}$ HMBC spectrum gave the following linkages (Figure 3a): (1) Cross-peaks from $\mathrm{H}_{2}-7^{\prime}(\delta 2.70,2.85)$ to $\mathrm{C}-1^{\prime}(\delta 110.7), \mathrm{C}-2^{\prime}(\delta 139.3)$ and $\mathrm{C}-3^{\prime}$ $\left(\delta\right.$ 102.2), from $\mathrm{OH}-4^{\prime}\left(\delta\right.$ 11.08) to $\mathrm{C}-3^{\prime}, \mathrm{C}-4^{\prime}(\delta$ 162.3) and C-5' $\left(\delta\right.$ 103.5) and from H-5' $\left(\delta\right.$ 6.30) to C-1', C- $3^{\prime}$, C- $4^{\prime}$ and C-6 $6^{\prime}(\delta$ 159.1) indicated that a phenol skeleton connects the partial structure I at $\mathrm{C}-2^{\prime}$. Furthermore, the findings that the chemical shift of C-8' $(\delta 74.7)$ corresponds to an oxygenated carbon and the $\mathrm{OH}-4^{\prime}$ proton $(\delta 11.08)$ shifted to a lower field because of a hydrogen bonding indicated that $\mathrm{C}-3^{\prime}$ and $\mathrm{C}-8^{\prime}$ are connected through an ester bond, which form $\delta$-lactone. This was also supported by the IR absorption (1619$\left.1666 \mathrm{~cm}^{-1}\right)$. Although observation of a cross-peak from $\mathrm{H}-8^{\prime}$ to C-10' $(\delta$ 169.9) was important and simple to show the presence of $\delta$-lactone, the cross-peak was not observed because the dihedral angle between $\mathrm{H}-8^{\prime}$ and $\mathrm{C}-10^{\prime}$ is $90^{\circ}$. Therefore, the coupling constant in $\mathrm{HMBC}$ experiment was changed from $J_{\mathrm{C}-\mathrm{H}}=8.0 \mathrm{~Hz}$ to $J_{\mathrm{C}-\mathrm{H}}=3.0 \mathrm{~Hz}$. As a result, the long-range coupling of ${ }^{4} \mathrm{~J}$ from $\mathrm{H}-5^{\prime}$ to $\mathrm{C}-10^{\prime}$ was observed, supporting the presence of $\delta$-lactone. (2) Cross-peaks from $\mathrm{H}_{2}-11(\delta 2.52)$ to $\mathrm{C}-8(\delta 79.0)$, from $\mathrm{H}_{3}-12(\delta$ 1.23) to $\mathrm{C}-7$ $(\delta$ 71.8), C-8 and C-9 $(\delta 43.0)$, from H-7 $(\delta 4.11)$ to C-8 and C-9, from $\mathrm{H}-9(\delta 2.23)$ to $\mathrm{C}-8, \mathrm{C}-10(\delta 36.2)$ and $\mathrm{C}-15(\delta 24.6)$, from $\mathrm{H}_{2}-6$

${ }^{1}$ Graduate School of Pharmaceutical Sciences, Kitasato University, Shirokane, Minato-ku, Tokyo, Japan and ${ }^{2}$ Kitasato Institute for Life Sciences, Kitasato University, Shirokane, Minato-ku, Tokyo, Japan

Correspondence: Professor H Tomoda, Graduate School of Pharmaceutical Sciences, Kitasato University, 5-9-1 Shirokane, Minato-ku, Tokyo 108-8641, Japan.

E-mail: tomodah@pharm.kitasato-u.ac.jp

Received 15 January 2009; revised 6 February 2009; accepted 19 February 2009; published online 20 March 2009 


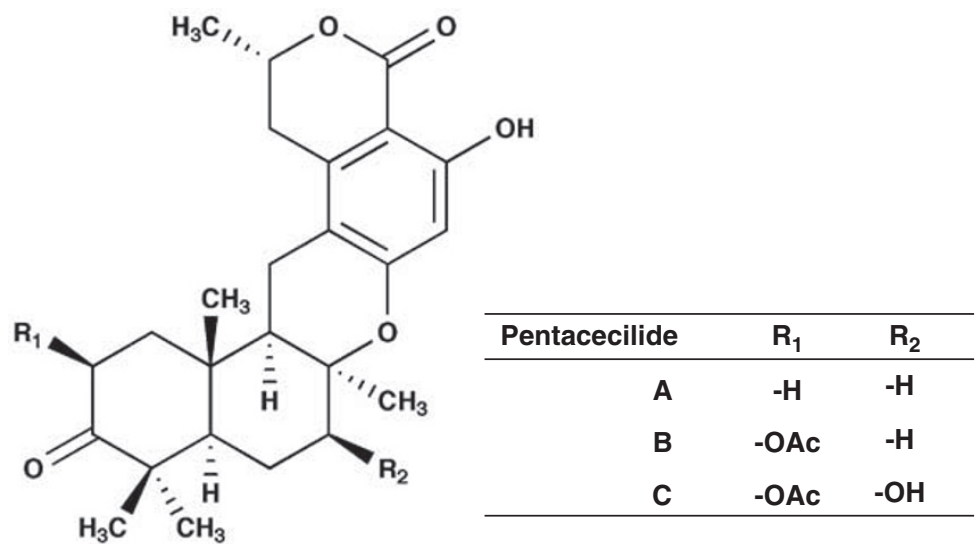<smiles>C[C@H]1Cc2c3c(cc(O)c2C(=O)O1)[C@@]1(C)[C@@H](O)C[C@]2(C)C(C)(C)C(=O)CC[C@]2(C)[C@]1(C)C3</smiles>

Thailandolide A<smiles>CC(=O)O[C@H]1c2c(c(O)cc3c2[C@]2(C)C[C@](C)(O3)[C@@H](O)C[C@@]3(C)C(C)(C)C(=O)C=C[C@@]23C)C(=O)O[C@@H]1C</smiles>

Thailandolide B

Figure 1 Structures of pentacecilides $\mathrm{A}$ to $\mathrm{C}$ and thailandolides $\mathrm{A}$ and $\mathrm{B}$.

Table 1 Physicochemical properties of pentacecilides A, B and C

\begin{tabular}{|c|c|c|c|}
\hline & Pentacecilide $A$ & Pentacecilide $B$ & Pentacecilide C \\
\hline Appearance & White crystalline solid & White crystalline solid & White crystalline solid \\
\hline Molecular weight & 412 & 470 & 486 \\
\hline Molecular formula & $\mathrm{C}_{25} \mathrm{H}_{32} \mathrm{O}_{5}$ & $\mathrm{C}_{27} \mathrm{H}_{34} \mathrm{O}_{7}$ & $\mathrm{C}_{27} \mathrm{H}_{34} \mathrm{O}_{8}$ \\
\hline \multicolumn{4}{|l|}{ HRESI-TOF-MS $(\mathrm{m} / \mathrm{z})$} \\
\hline Calcd: & $435.2147(\mathrm{M}+\mathrm{Na})^{+}$ & $493.2225(\mathrm{M}+\mathrm{Na})^{+}$ & $509.2151(\mathrm{M}+\mathrm{Na})^{+}$ \\
\hline Found: & $435.2141(\mathrm{M}+\mathrm{Na})^{+}$ & $493.2202(\mathrm{M}+\mathrm{Na})^{+}$ & $501.2162(\mathrm{M}+\mathrm{Na})^{+}$ \\
\hline UV $(\mathrm{MeOH}) \lambda_{\max } \mathrm{nm}(\varepsilon)$ & 219 (18647), 274 (11846), 309 (4194) & 219 (33055), 274 (18226), 309 (4784) & 214 (54432), 273 (32736), 310 (4947) \\
\hline$[\alpha]^{6}$ & $-4.38^{\circ}\left(c=0.38, \mathrm{CHCl}_{3}\right)$ & $-32.6^{\circ}\left(c=0.68, \mathrm{CHCl}_{3}\right)$ & $-32.3^{\circ}\left(c=0.48, \mathrm{CHCl}_{3}\right)$ \\
\hline $\mathrm{IR}(\mathrm{KBr}) v_{\max }\left(\mathrm{cm}^{-1}\right)$ & $3401,1697.1662,1465,1380$ & $3440,1747,1727,1666,1475$ & $3434,1745,1666,1619,1473$ \\
\hline
\end{tabular}

$(\delta 1.86,2.18)$ to $\mathrm{C}-10$, from $\mathrm{H}_{3}-15(\delta 1.54)$ to $\mathrm{C}-9, \mathrm{C}-10$ and $\mathrm{C}-1(\delta$ $41.1)$, from $\mathrm{H}-5(\delta 1.82)$ to $\mathrm{C}-4(\delta 48.3), \mathrm{C}-10$ and $\mathrm{C}-15$, from $\mathrm{H}_{2}-1(\delta$ $1.88,2.20)$ to $\mathrm{C}-3(\delta 207.8), \mathrm{C}-5, \mathrm{C}-10$ and $\mathrm{C}-15$, from $\mathrm{H}_{3}-13(\delta 1.14)$ to C-3, C-4, C-5 and C-14 ( $\delta$ 25.7), from $\mathrm{H}_{3}-14(\delta 1.20)$ to C-3, C-4, $\mathrm{C}-5$ and $\mathrm{C}-13(\delta 20.8)$ and from $\mathrm{H}-2(\delta 5.63)$ to $\mathrm{C}-3$ showed the presence of a 3 -oxo-decalin skeleton containing the partial structures II to IV. (3) Cross-peaks from $\mathrm{H}-2$ and $\mathrm{H}_{3}-17(\delta$ 2.17) to $\mathrm{C}-16(\delta$ $170.3)$ showed that an acetoxy group is connected to C-2. The chemical shift of C-7 $(\delta$ 71.8) and the molecular formula showed the presence of a hydroxy group. (4) The finding that cross-peaks were observed from $\mathrm{H}-11$ to $\mathrm{C}-1^{\prime}, \mathrm{C}-2^{\prime}$ and $\mathrm{C}-6^{\prime}$ and that the chemical shifts of C-8 $(\delta 79.0)$ and C-6' $(\delta$ 159.1) correspond to an oxygenated carbon indicated that a phenol and a decalin ring are connected by a pyran ring. The pentacyclic structure was found to consist of a sixmembered lactone, a phenol, a pyran and a decalin ring. Thus, the structure of pentacecilide $\mathrm{C}$ was elucidated as shown in Figure 1. The structure satisfied the degree of unsaturation and the molecular formula. Furthermore, all chemical shifts, except for C-2 in pentacecilide C, were comparable with those reported for thailandolide $\mathrm{A}^{2}$ 
Table $2{ }^{1} \mathrm{H}$ and ${ }^{13} \mathrm{C}$ NMR chemical shift of pentacecilides A, B and C

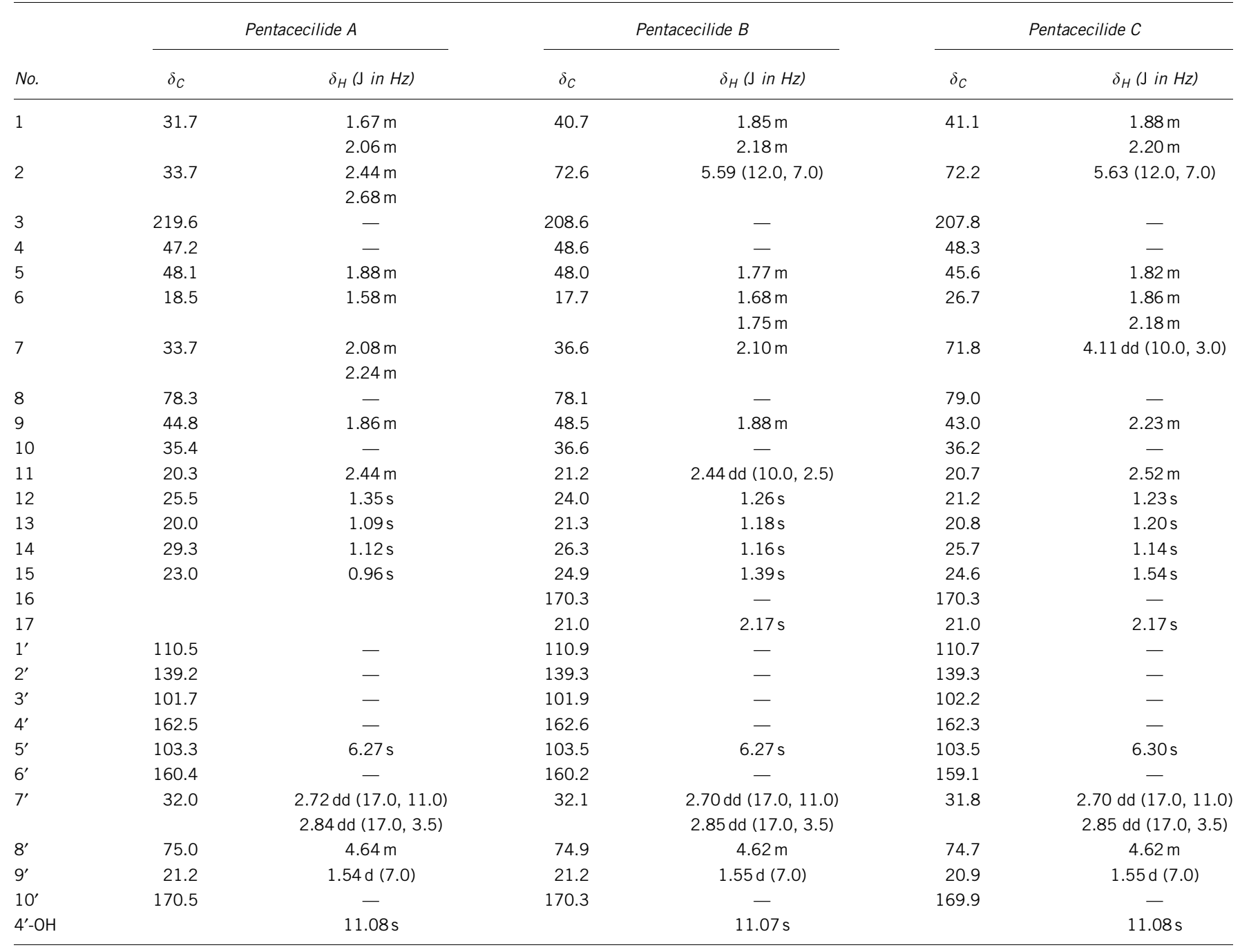

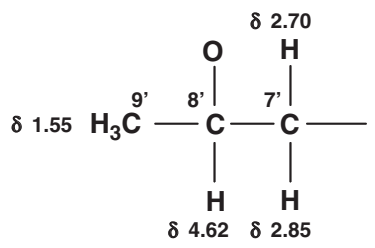

I

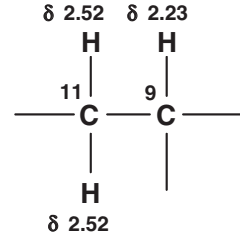

II

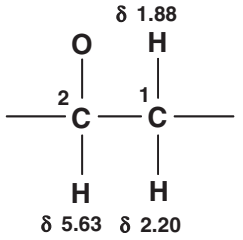

IV

Figure 2 Partial structures of pentacecilide C.

Structure elucidation of pentacecilide $\mathrm{B}$

The molecular formula $\mathrm{C}_{27} \mathrm{H}_{34} \mathrm{O}_{7}$ of pentacecilide $\mathrm{B}$ is smaller by one oxygen atom than that of pentacecilide C. Comparison of the ${ }^{1} \mathrm{H}$ NMR spectra between pentacecilides $\mathrm{B}$ and $\mathrm{C}$ indicated that the oxygenated $s p^{3}$ methine proton ( $\left.\mathrm{H}-7\right)$ in pentacecilide $\mathrm{C}$ is replaced by methylene protons $(\delta 2.10)$ in pentacecilide B. In fact, analyses of the ${ }^{1} \mathrm{H}-{ }^{1} \mathrm{H}$ COSY revealed the presence of the partial structure $\mathrm{V}$ containing the replaced part (Figure $3 \mathrm{~b}$ ). The partial structure $\mathrm{V}$ was also confirmed by observing cross-peaks from $\mathrm{H}_{3}-12(\delta 1.26)$ to $\mathrm{C}-7$ $\left(\delta\right.$ 36.6), C-8 $\left(\delta\right.$ 78.1) and C-9 $\left(\delta\right.$ 48.5), from $\mathrm{H}_{2}-7(\delta 2.10)$ to C-8, from $\mathrm{H}-9(\delta 1.88)$ to $\mathrm{C}-8, \mathrm{C}-10(\delta 36.6)$ and $\mathrm{C}-15(\delta 24.9)$, from $\mathrm{H}_{2}-6$ $(\delta 1.68,1.75)$ to $\mathrm{C}-10$, from $\mathrm{H}_{3}-15(\delta 1.39)$ to $\mathrm{C}-9$ and $\mathrm{C}-10$ and from $\mathrm{H}-5\left(\delta\right.$ 1.77) to $\mathrm{C}-10$ in ${ }^{13} \mathrm{C}-{ }^{1} \mathrm{H}$ HMBC experiments (Figure $3 \mathrm{~b}$ ). Taken together, the structure of pentacecilide $\mathrm{B}$ was elucidated as 7-dehydroxy pentacecilide C (Figure 1).

\section{Structure elucidation of pentacecilide $\mathrm{A}$}

The molecular formula $\mathrm{C}_{25} \mathrm{H}_{32} \mathrm{O}_{5}$ of pentacecilide $A$ is smaller by $\mathrm{C}_{2} \mathrm{H}_{2} \mathrm{O}_{3}$ than that of pentacecilide C. Comparison of the ${ }^{1} \mathrm{H}$ NMR spectra of pentacecilides $\mathrm{A}$ and $\mathrm{B}$ showed that the methyl protons $\left(\mathrm{H}_{3}-17\right)$ disappear and the oxygenated $s p^{3}$ methine proton $(\mathrm{H}-2)$ is 


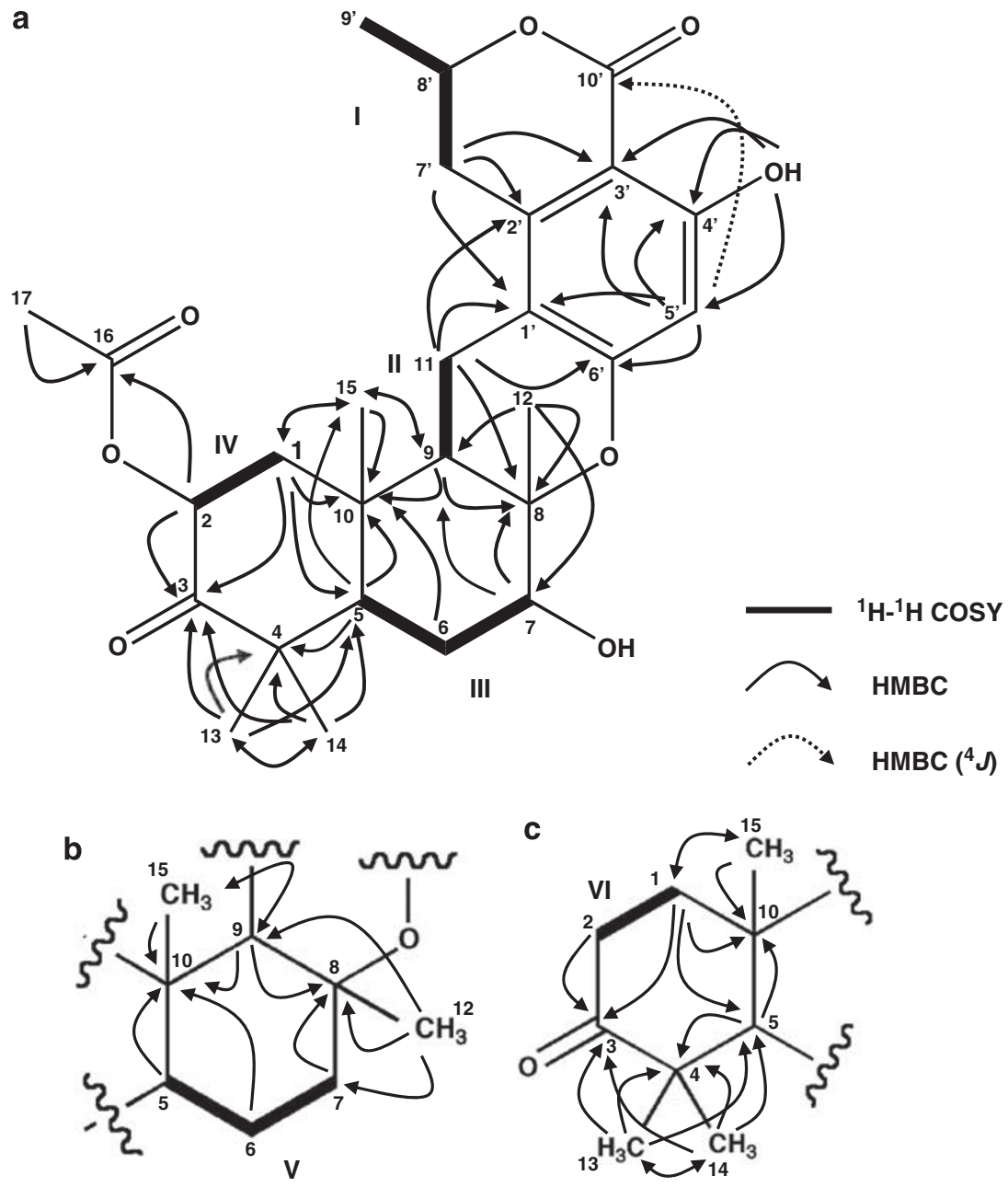

Figure $3{ }^{1} \mathrm{H}-{ }^{1} \mathrm{H}$ COSY and ${ }^{13} \mathrm{C}-{ }^{1} \mathrm{H}$ HMBC experiments of pentacecilides $\mathrm{A}(\mathbf{a}), \mathrm{B}(\mathbf{b})$ and $\mathrm{C}(\mathbf{c})$.

replaced by methylene protons $(\delta 2.44,2.68)$. Analyses of the ${ }^{1} \mathrm{H}-{ }^{1} \mathrm{H}$ COSY revealed that the partial structure VI contains the replaced part (Figure 3c). The partial structure VI was also confirmed by observing cross-peaks from $\mathrm{H}_{3}-15(\delta$ 0.96) to $\mathrm{C}-1(\delta 31.7)$ and $\mathrm{C}-10(\delta 35.4)$, from $\mathrm{H}-5(\delta 1.88)$ to $\mathrm{C}-4(\delta 47.2)$ and $\mathrm{C}-10$, from $\mathrm{H}_{2}-1(\delta 1.67,2.06)$ to $\mathrm{C}-3\left(\delta\right.$ 219.6), C-5 $(\delta 48.1), \mathrm{C}-10$ and C-15 $(\delta 23.0)$, from $\mathrm{H}_{3}-13(\delta$ $1.09)$ to $\mathrm{C}-3, \mathrm{C}-4, \mathrm{C}-5$ and $\mathrm{C}-14(\delta 29.3)$, from $\mathrm{H}_{3}-14(\delta 1.12)$ to $\mathrm{C}-3$, C-4, C-5 and C-13 (20.0) and from $\mathrm{H}_{2}-2$ to $\mathrm{C}-3$ in ${ }^{13} \mathrm{C}-{ }^{1} \mathrm{H}$ HMBC experiments (Figure $3 \mathrm{c}$ ). Taken together, the structure of pentacecilide A was elucidated as 2-deacetoxy pentacecilide B (Figure 1).

\section{Stereochemistry of pentacecilides}

Pentacecilide $\mathrm{C}$ has seven chiral carbons in its structure. The relative stereochemistry at C-2, C-5, C-7, C-8, C-9 and C-10 of the tricyclic skeleton (A-B-C) was investigated by NOESY experiments. As shown in Figure 4, cross-peaks were observed between $\mathrm{H}-2(\delta 5.63)$ and $\mathrm{H}_{3}$ $13(\delta 1.20) / \mathrm{H}_{3}-15(\delta 1.54)$, between $\mathrm{H}_{3}-15$ and $\mathrm{H}_{a x}-6(\delta 2.18) / \mathrm{H}_{3}-13$, between H-5 $(\delta 1.82)$ and $\mathrm{H}-7(\delta 4.11) / \mathrm{H}-9(\delta 2.23)$ and $\mathrm{H}-7$ and $\mathrm{H}-9$, indicating that they are oriented in a 1,3-diaxial conformation. Accordingly, rings $\mathrm{A}$ and $\mathrm{B}$ are oriented in a chair-chair form. Secondly, cross-peaks were observed between $\mathrm{H}_{3}-12(\delta$ 1.23) and $\mathrm{H}-7 / \mathrm{H}_{2}-11\left(\delta\right.$ 2.52) and between $\mathrm{H}_{3}-15$ and $\mathrm{H}_{2}-11$, suggesting that rings $\mathrm{B}$ and $\mathrm{C}$ are oriented in a chair-boat form. Thirdly, cross-peaks were observed between $\mathrm{H}_{e q^{-}} 7^{\prime}\left(\delta\right.$ 2.85) and $\mathrm{H}-11 / \mathrm{H}-8^{\prime}(\delta$ 4.62) and

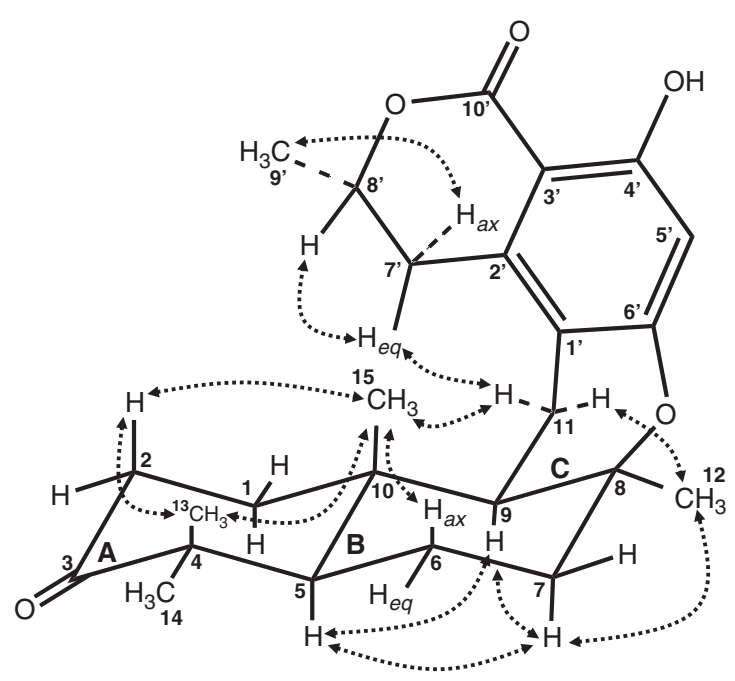

NOESY

ax; axial eq; equatorial

Figure 4 NOESY experiments of pentacecilide C. 
between $\mathrm{H}_{a x}-7^{\prime}$ and $\mathrm{H}_{3}-9(\delta 1.55)$, indicating that the conformation of $\mathrm{H}_{3}-9^{\prime}$ is equatorial, which was also supported by a large coupling constant $(J=11 \mathrm{~Hz})$ between $\mathrm{H}_{a x}-7^{\prime}$ and $\mathrm{H}-8^{\prime}$. Taken together, the relative stereochemistry of pentacecilide $\mathrm{C}$ was determined as shown in Figure 1. These results were consistent with those of thailandolide A except for the stereochemistry at C-8', although chemical shifts at $\mathrm{C}-8^{\prime}$ of pentacecilide $\mathrm{C}$ and thailandolide A were almost the same. ${ }^{2}$

The relative stereochemistry of pentacecilides A and B was deduced to be the same as that of pentacecilide $\mathrm{C}$ by the similarity of NOESY experiments and the coupling constants in ${ }^{1} \mathrm{H}$ NMR.

\section{DISCUSSION}

Pentacecilides A to C, structurally related to thailandolides, were isolated from the culture broth of P. cecidicola FKI-3765-1, and were found to have a common pentacyclic core containing an aromatic ring and a $\delta$-lactone ring. The core seemed to be a meroterpene, consisting of a sesquiterpene and a pentaketide. Thailandolides were reported to be produced by Talaromyces thailandiasis, ${ }^{2}$ whereas pentacecilides were produced by a different genus Penicillium. Thailandolides A and B were not detected in the culture broth of P. cecidicola FKI-3765-1.

From the structure elucidation, the planar structures of pentacecilides were seen to be similar to those of thailandolides. The relative stereochemistry of the compounds is almost the same, but the C- $8^{\prime}$ stereochemistry is different; the C- $8^{\prime}$ methyl group of thailandolides is oriented in the axial conformation, ${ }^{2}$ whereas that of pentacecilides is in the equatorial conformation.

\section{METHODS}

\section{General experimental procedures}

UV spectra were recorded on a spectrophotometer (8453 UV-Visible spectrophotometer, Agilent Technologies Inc., Santa Clara, CA, USA). IR spectra were recorded on a Fourier transform infrared spectrometer (FT-710, Horiba Ltd, Kyoto, Japan). Optical rotations were measured with a digital polarimeter (DIP-1000, JASCO Corporation, Tokyo, Japan). ESI-TOF-MS and HRESITOF-MS spectra were recorded on a mass spectrometer (JMS-T100LP, JEOL Ltd, Tokyo, Japan). Various NMR spectra were measured with a spectrometer (XL-400, Varian Inc., Palo Alto, CA, USA).

\section{ACKNOWLEDGEMENTS}

This study was supported by the Program for the Promotion of Fundamental Studies in Health Sciences (to HT) from the National Institute of Biomedical Innovation (NIBIO). We express our thanks to Ms N Sato for measuring NMR experiments, and $\mathrm{Mr} \mathrm{K}$ Nagai and Ms A Nakagawa for measuring mass spectra. We also thank Mr N Ugaki for excellent technical assistance.

1 Yamazaki, $\mathrm{H}$ et al. Pentacecilides, new inhibitors for lipid droplet formation in mouse macrophages produced by Penicillium cecidicola FKI-3765-1. I. Taxonomy, fermentation, isolation and biological properties. J. Antibiot. 62, 195-200 (2009).

2 Dethoup, T et al. Merodrimanes and other constituents from Talaromyces thailandiasis. J. Nat. Prod. 70, 1200-1202 (2007) 